\title{
On the Importance of History and Historicity in the (Socio-)Linguistic Reconstruction of Pidgins and Creoles: The Case of the Original Lingua Franca
}

\author{
Manuel Sedlaczek*
}

\begin{abstract}
The term "lingua franca" originally derives from an ancient Mediterranean language which was indeed called the Lingua Franca. The Lingua Franca was a commercial or trading language used at sea and in the ports of the Mediterranean basin ever since the $16^{\text {th }}$ century. The paper outlines its history, deliberates the available sources of insight, and discusses the importance of historicity in sociolinguistic studies.
\end{abstract}

Key words: lingua franca, Lingua Franca, historicity, sociolinguistics, pidgins, creoles, historical linguistics

* Alpen-Adria-Universität Klagenfurt; msedlacz@edu.aau.at 


\section{Introduction}

The study of Pidgins and Creoles offers a great variety of different topics and issues to be investigated in the field of linguistics. One such topic and issue is a linguistic entity designated as "lingua franca", which was defined by the Pidgin and Creole specialist Hugo Schuchardt as "any widely-spread commercial argot" (Schuchardt 1979, 32). A lingua franca, therefore, is a language that is used by a considerable number of people for basic/everyday communication purposes only and therefore is not necessarily spoken with a traditional native-speaker competence. One may think of English as a global lingua franca, as English is widespread in the world and has also become a means of communication for people with different mother tongues. Fascinating as it is, the spoken form of English used as a lingua franca by such speakers may or may not be similar to the distinctive structure of Pidgins and Creoles themselves. However, the term "lingua franca" originally derives from an ancient Mediterranean language which was indeed called the Lingua Franca. The Lingua Franca was a commercial or trading language used at sea and in the ports of the Mediterranean basin ever since the $16^{\text {th }}$ century. The Lingua Franca is also said in its turn to form the genesis of Pidgins and Creoles itself. Indeed, some theories suggest that the Lingua Franca is the Ur-Pidgin from which all Pidgins and Creoles derive (Hancock 1977; Thompson 1961; Whinnom 1984). Ur-Pidgin or not, the Lingua Franca plays an important role in the study of Pidgins and Creoles and a number of theories about the significance of the Lingua Franca for the formation of Pidgins and Creoles have evolved. In any case, the Lingua Franca deserves close attention in the study of contact-derived languages and should also be studied seriously when focusing on the analysis of Pidgins and Creoles as such, whether English-lexified or other language-lexified.

It will be the purpose of the following to give a reconstruction of the origin, spread, and development of the Lingua Franca. Since historical evidence is immanent in the reconstruction of the Lingua Franca, this article will start with a survey of the Lingua Franca. Furthermore, a sociohistorical description of the Lingua Franca, how it developed, what it was (a language used for commerce, slavery, and chancery) and how much importance and impact it had on Mediterranean trade will be included. One aim of this article then is to give a detailed description of the events that led to the creation and establishment of the Lingua Franca.

\section{The Study of the Lingua Franca}

The study of the Lingua Franca is not new. Schuchardt (1909) was the first to seriously study the Lingua Franca, but there still remains much detail to be discovered. One such detail is the question concerning its origin. Many scholars have undertaken different approaches to this question and have developed a variety of theses, but not much general 
agreement has been reached concerning its origin. Many questions remain unanswered. Many opinions exist and scholars have wondered "how light could be thrown on the whole issue" (Le Page 1961, 126). One suggestion has been that detailed work still needs to be done which should be "descriptive and historical" and "every effort should be made" to cover not only the language itself "but also the history and structure of the society" in which it emerged in addition to its development by means of historical and comparative linguistics (ibid., 126ff.). Unfortunately, historical aspects have been neglected even though in most cases the historical evidence is available.

Therefore, scholars like Arends demand "a historically realistic theory of creole formation" $(2002,56)$. Such a theory, according to him, should "be in agreement with the historical facts" (ibid.). Arends also mentions that historical evidence should play an essential role in the "evaluation of theories based on purely linguistic considerations" (ibid.). The erroneous belief that the evolution and development of a language is ("paradoxically”) regarded "as an 'a-temporal' process" (ibid., 58), where time seems to be irrelevant and therefore completely ignored, is (according to Arends) not only "unwarranted to maintain" but also "hardly defensible at any time" (ibid.). His final statement is that "historical correctness is not a frequently found feature" (ibid., 56).

Another scholar who asks for more historicity is John Wansbrough (1996), who states that linguistic models are still far too theoretical in this sense, as they are "methodologically useful but historically exiguous" $(1996,148)$. Wansbrough also states that the theoretical construct associated with historical linguistics, the comparative method, has indeed been in use "since this has never proved especially difficult" but it only serves "to provide regularity with a diachronic dimension" (ibid., 156). So, in this sense it may only give (predetermined) answers to predetermined questions and the main theory still remains speculative, as this kind of "reconstruction can never be other than conjectural" (ibid.). Wansbrough therefore calls for the "historical reconstruction of contact" (ibid., 151), as this can eliminate the speculative factor to a certain extent and unlikely possibilities of development can be ruled out. Among others who suggest an approach to Pidgins and Creoles dealing much more with history is, for example, Robert Le Page (1961) who claims that linguistic work should be both "descriptive and historical" as mentioned above, and should cover the "history and structure of the society in which it is spoken" (ibid., 127).

A substantial history of the origin and development of the Lingua Franca is therefore lacking, and if it is dealt with at all in the literature, it is only considered briefly. Because of this "lack of history" in linguistic approaches to the problem, the starting point of the present discussion will be the classical anthropological approach (to history).

Anthropology has developed from many sciences, but one of the major elements is natural history. An anthropological approach draws on many fields such as history, linguistics, sociology and others. Furthermore, as much as anthropology developed out of, and draws on, many sciences it has also developed further to itself influence fields including sociolinguistics and historical linguistics. These sciences may be seen, therefore, 
as a combination of anthropology and linguistics, as, for instance, seen with traditional Anthropological Linguistics (cf., e.g. Sapir 1921) and even more so with modern Linguistic Anthropology (cf, e.g. Agha 2006). The impact of linguistics on anthropology and vice versa shows that both share common interests, since "in linguistics and in social sciences the role of language is assumed and asserted" (Hymes 1971, 49).

However, there does not seem to be a close cooperation of sociolinguistics and historical linguistics "although there is a great need for that" (ibid., 50). Such cooperation would lead us to insightful conclusions on the development of languages. The historical linguistic approach is important to gain insights into a (past) society as it considers changes which, as a result, also explain changes in language. Ironically, neither natural history nor anthropology nor its subgroups take the actual history itself of its objective of study into consideration even though anthropology originally developed in part from the field of history.

This paradox can be ascribed to the state of anthropology in the $19^{\text {th }}$ century. The concept of "history", as well as "historicity" was rejected by many anthropologists, and consequently by historical linguists and sociolinguists because of a misunderstanding. This misunderstanding which was meant to reject models that offered fake historicity actually caused the rejection of history itself. The models that were created out of this misunderstanding rather "created" history than actually reconstructing it. The most prominent model, the Neogrammarian model, failed to predict history and instead created "a 'possible' past within historical linguistics but not a 'real' past" (Ardener 1971, 211). Linguists, then, turned their back on true history also because it could not offer them any theoretical insights, so the argument went, as a consequence of the lack of relevant competent models. There was indeed a problem with history (and historicity). The Neogrammarian model, for example, was not a model of history, as it does not offer actual history but generates it from forms that were not previously attested. These were a kind of guess, historically speaking, i.e. a theory of history without attested facts about history and therefore "the Neogrammarian model generates more 'history' than it puts in" (ibid., 215). A historical explanation to linguistic genesis, the most obvious solution, however, was not sought. This, by contrast, will be the main intention of this article, i.e. to give a historical explanation of the origin, development, and spread of the Lingua Franca.

\section{Problems Specifically Concerning the Lingua Franca}

The Lingua Franca is quite an old language that has existed for (almost) half a millennium. However, very little is known about its origin, development, and spread and therefore many views concerning the origin of the Lingua Franca exist. One view is that "the Lingua Franca originated at the time of the Crusades (A.D. 1095ff.) on the Jerusalem battlefields" and continuously spread westward "along the shores of the 
Mediterranean" (Hancock 1977, 283) through military and merchant activity as well as piracy and slavery later on in the $16^{\text {th }}$ century. According to Wansbrough (1996), the Lingua Franca established itself as a language of commerce ensuring communication between the cultures of the Mediterranean. However, despite continuous contact and establishment of the language, very few documents of and linguistic evidence about the Lingua Franca have survived.

Although the history of the Lingua Franca itself is quite obscure, the probability that such a language was spoken throughout the Mediterranean is quite high, but there is hardly anything concrete to confirm this. The Lingua Franca shares the fate of many Pidgins and Creoles that are known today but which were never "adequately recorded" (Hancock 1977, 279) or described. It seems the Lingua Franca and its use in the Mediterranean was such a matter of course on the one hand that no one felt the need to write about it or even to just mention it, and it was at the same time efficient enough on the other hand that people used it without hesitation. Presumably, the Lingua Franca was not a language of prestige, i.e. not used in science or education and thus neither scholars nor educated people saw the necessity to further indulge in the study of such a language.

As will be seen, the Lingua Franca most likely developed out of commerce. It was a neutral language that was simple, quick, and effective. It was used for trade, for communication between slavers and slaves, and even in the field of diplomacy. The Lingua Franca was practical and effective and, as already suggested, this just might be the reason for its "insignificance". It was never adequately recorded or studied until the $19^{\text {th }}$ century (Schuchardt 1909) and, ironically, it ceased to exist shortly after academic interest had emerged.

As already indicated, in the course of the historical reconstruction of the origin and development of the Lingua Franca many uncertainties have arisen due to a lack of documentation, due to the need to resort to other, less specific, documents and also due to a lack of interest at various stages in the history of the language. In short, in tracing the origin of the Lingua Franca one seeks a "resolution of an historical problem, that is altogether unsatisfactory,” (Wansbrough 1996, 25), as many questions remain unanswered. Reconstructing the origin and development of the Lingua Franca through history is a complicated task, as many details, unfortunately, remain unclear due to historical gaps created through the aforementioned limited sources or limited documentation itself, i.e. "evidence is often meagre or indeed unavailable" (ibid., 77). The gaps in history are "so frequent and so exasperating" that "the very fact of recurrence might be thought to entail some regularity" (ibid.). The safest conclusion that can be drawn from this recurrence of the Lingua Franca in the course of history is that what is unattested can be regarded as "gaps in a continuum" (ibid.).

In the majority of cases, the most necessary documents that are relevant to the origin of the Lingua Franca are missing, either because a document may have been lost in history or is simply not available. In these situations, interpretations are one possibility of solving such a problem, especially regarding that of the origin of the Lingua Franca. This 
is where searching for revealing sources needs to be extended to history itself, as historical research allows further and, probably, more accurate interpretations. By looking not only at the available (relevant) sources but, at the same time, also at the historical events that accompanied these developments, it is possible to make logical interpretations and gain further insights. To make such logical interpretations, "circumstantial evidence" (de Granda 1976, 13) needs to be consulted. Only by demonstrating the historical plausibility of certain developments is it possible to prove "that the postulated causal series actually could take place" (ibid., 17).

It is through "historical analysis" (ibid.) that the obstacles of limited availability and limitation of these documents themselves can be overcome. After all, most developments of important historical events, in this case the origin and development of the Lingua Franca, are not a coincidence. The formation of the Lingua Franca was not unintended or merely an accident. The Lingua Franca was the logical consequence of a sequence of historical events and then became only one further event in a chain of many other historical developments. What is most essential and most difficult is to not confuse the "real conditioning factors with the monetary situation" (Chaunu 1979, 291).

Wansbrough clearly states that "as nearly always, the real problem is in depicting not the product but the process" $(1996,77)$. In the case of the Lingua Franca, it is not difficult to state its existence, but the long and continuous duration and continuity of its existence and, most of all, an exact statement of the origin of the Lingua Franca or the events or processes that led to its (supposed) creation is hardly possible. Even a statement about the events in history that influenced the Lingua Franca or its course in history is very difficult. Which events changed the Lingua Franca and why it was considered as unimportant is a very complex question that cannot simply be answered without resorting to history, historical analysis, and historical plausibility itself. From the available documents alone it is only possible to state that the Lingua Franca continued to reappear, time and time again, for centuries, as there are references to the existence of the Lingua Franca in all kinds of documents. However, a clear statement from such documents alone cannot be deduced because most of these references are merely side notes or not extensive enough to give detailed information about origin, development, or diffusion of the Lingua Franca.

\subsection{The Discontinuity of Documentation}

Although "for some languages concrete historical evidence is lacking" (Hancock 1977, 282), through linguistic clues we are able to reconstruct their history, such as the time or circumstances of their origin. For other languages, it is the other way around. We possess historical evidence of their existence but lack any concrete linguistic data. The Lingua Franca is such a case where documentation clearly proves its existence early in time (about the $16^{\text {th }}$ century), but where very little evidence of its linguistic traits has survived. Linguistic documents about the Lingua Franca are sparse and everything be- 
fore 1600 hardly qualifies as what could be called a "linguistic description" (Wansbrough 1996, 149). The majority of the written linguistic evidence that is available is not "much older than a century or two" and "early documentation is especially scant" (Hancock 1977, 278). For the even earlier period there is no substantial linguistic evidence, as the Lingua Franca has not been "adequately recorded throughout its development" (ibid., 279). For the most part, the Lingua Franca is only mentioned or hinted at. These socalled hints are often "reports of pilgrims blessed with the gift of tongues" (Wansbrough 1996, 148). It may be necessary to mention that at least these hints are "plentiful” (ibid.). These reports are about the lives of saints, crusaders, pilgrims, about expeditions, merchants, overseas garrisons and the like. There are various passages where saints were speaking a lingua franca to communicate with other people along their way. Many of these documents state that often there was no need for an interpreter, as some possessed "the gift of tongues" (ibid.) or had received "the grace of languages" (Hancock 1977, 285). However, as no examples of these languages are given, it remains unclear if it really was the Lingua Franca or if it was some (other) lingua franca of the time such as "Vulgar Latin" or "Targumic" or some other trade or contact language. Although there is a (slight) possibility that it could have been the Lingua Franca, there still is no final evidence to confirm this.

While reconstructing the later development of the Lingua Franca is already a difficult task, it is easy to imagine that it is nearly impossible to reconstruct the earlier period or even the beginnings of the Lingua Franca from linguistic evidence alone. Depending on what century is looked at, the sources are either scarce or hardly available. However, as a general rule it can be stated that the further we go back in time the less documentation is available. There are also temporal 'lacunae' (Wansbrough 1996) and other gaps in documentation that might create a false impression, i.e. the impression that there was no continuity in trade and communication in the Mediterranean basin.

This state of affairs can be ascribed to the "random density pattern" (ibid., 52) in which the Lingua Franca has been documented. However, this so-called "lack of continuity" created due to the lack of documentation is itself "nothing more than a product of the historical residue" (ibid.), and "it would of course be irresponsible to infer from lack of typical documentation the absence of such activity" (ibid.). From the lack of documents alone we cannot conclude the absence of continuity in the use of the Lingua Franca, especially not since the Lingua Franca reappears, time and time again, in the course of history after centuries of missing documented proof and indeed, "after all we cannot consider the absence of documents in Lingua Franca as proof of its nonexistence" (Whinnom 1984, 302).

There are thus many lacunae and gaps concerning the history of the Lingua Franca and so much of speculation has been undertaken about its origins and its development. As will be gathered, linguistic documentation is far too "inconclusive" to allow more than a hypothesis, as "much still remains unproven" (Hancock 1977, 278). This is also the crucial point, after all, "it is nonetheless important to recall that [a] conclusion can- 
not rest upon a hypothetical construct" (Wansbrough 1996, 6). Therefore, there has to be an "escape from this linguistic prison" (ibid., 8). Instead of basing reconstruction of the Lingua Franca on linguistic evidence alone we should seek an alternative. The origin and development of the Lingua Franca "might be constructed by resort to accessible but different data" (ibid., 17) so that lacunae, or historical gaps, can be "filled from other kinds of source material" (ibid., 52). Resorting to other documents, which are quite often unrevealing or even ambivalent, is not without problems (cf. ibid., 40). Ironically, this rather leads to an abundance of potential source texts and Wansbrough (1996) states that it is this abundance of documentation "that generates a range of defensible interpretation rather than a single "correct" version" (6). Indeed, further source texts do offer valuable insights into a range of topics concerning the Lingua Franca and its (social and political) environment.

One possibility is to resort to available poetry and ordinary prose texts. However, one must be careful when dealing with such potentially ambivalent sources, as it is essential to decide what is important and what is irrelevant to tracing Lingua Franca history. What might be useful and what might not be helpful is a question not easily answered. Literary evidence may be very helpful and easily accessible but it "can also be deceptive" (Wansbrough 1996, 40). Undoubtedly there is a dilemma one has to face when "dealing with distinct genres" (ibid.), as in this case linguistic research dealing with prose or poetry. The problem is that these genres allow a true representation of the Lingua Franca only to a certain degree, i.e. affecting the reliability of such documents. One must be aware, for poetry (as well as for stage plays) at least, that an author may have distorted the linguistic evidence to achieve a comic or dramatic effect or he may have misinterpreted the linguistic evidence due to a lack of knowledge of the Lingua Franca. Moreover, he may have adapted the Lingua Franca to make his work easily understandable for an audience that had no knowledge of the Lingua Franca. The samples, written in verse form, of the Lingua Franca that can be found in poetry were "hardly ever produced by writers thoroughly acquainted with the language" (Whinnom 1984, 296). Many such verses produced in the $16^{\text {th }}$ century (and later) can hardly be interpreted or be regarded as representative of the Lingua Franca, as they were on the one hand "written with [the] intent to amuse their Romance-speaking readers" (ibid.) and on the other hand only show "the writer's ignorance and native linguistic habits" (ibid.). Poetry does not necessarily reflect the reality of the Lingua Franca in the earlier period.

Also, in the $16^{\text {th }}$ and $17^{\text {th }}$ centuries it was customary to portray the Lingua Franca in a slightly distorted way. As Schuchardt (1979) says about the $16^{\text {th }}$ century: "[T]his was the century when one loved to hear all manner of broken Italian, naturally with the appropriate caricature, from the stage" $(1979,33)$. It seems clear from this statement that the Lingua Franca was not (always) portrayed accurately. This was definitely on purpose, just like in the well-known play by Moliere Le Bourgeois Gentilhomme (Moliere 
1670 quoted in Cifoletti 2004, 266) ${ }^{1}$. According to Schuchardt, the inaccuracy of the portrayal of the Lingua Franca in Moliere's play as used by the Turkish Mufti character, and also in other plays as well, serves "to add [a] dramatic effect and which is therefore not very reliable in its details" $(1979,34)$.

Another example would be the poem of the Zerbitana $(1353)^{2}$, which does show forms used in the later documented Lingua Franca such as "barra fuor" - 'get out' (Schuchardt 1979, 33). Curiously, it uses both the Italian infinitive form 'parlare' but also the (presumably) Lingua Franca form 'parlar', but with the Italian form always occurring at the end of the line. What would be an indication that this was primarily a poem and not a linguistically accurate description is the metre (of the poem) and the fact that in the poem itself the infinitives at the end of the line always end with the Italian infinitive forms such as parlare and conciare, but use the Lingua Franca (or Catalan) infinitive form in the beginning, e.g. parlar and voler (Zerbitana 1353 quoted in Collier 1977, 295) ${ }^{3}$. The poem of the Zerbitana (1353) could show possible similarities to Catalan, i.e. "the expression mia is very typical for Old Catalan as it has only been changed to mena and meva in later centuries" (Monk 2013,215). However, there is no unambiguous proof that this is the Lingua Franca itself (Zerbitana 1353 quoted in Collier 1977, 295). Schuchardt (1979) has analysed this poem and states that the only Arabic expression is barra followed by an Italian word fuor "barra fuor" (Schuchardt 1979, 33) which would allow this assumption of a Lingua Franca connection but is not enough to be considered as proof.

Concerning prose, the situation is quite comparable. We are confronted with a similar, but not quite identical problem in a different medium of documentation, i.e. in eyewitness reports and travelogues where references to the Lingua Franca and sometimes even linguistic evidence can be found. The travelogue itself is quite an old art form that was "popular even in the Arabian Empire around the $7^{\text {th }} / 8^{\text {th }}$ century" (Wansbrough 1996, 149) when it had its literary peak. The few references to, and linguistic evidence of, the Lingua Franca that one can find in travelogues date from the $7^{\text {th }}$ to the $19^{\text {th }}$ century. Travelogues were very popular not only in the Arabian Empire but their popularity continued far outside the Arabic world, albeit in later centuries. Unfortunately, even if there is something written that could be classified as "linguistic evidence", it is mostly not written by a linguist and presumably distorted, misinterpreted, and most

\footnotetext{
1 Si ti sabir Mi star Mufti

Ti respondir Ti qui star ti

Si non sabir Non intendir

Tazir, tazit Tazir, tazir

2 The term Zerbitana depicts a name as the first line of the poem ' $\mathrm{O}$ la Zerbitana retica' translates to "Heretical Zerbitana" (Lang, 1992, 68)

3 O la Zerbitana retica? Oi Zerbitana retica, Il parlar ch' ella mi dicia ! : come ti voler parlare? "Per tutto lo mondo fendoto, se per li capelli prendoto, E barra fuor casa mia”. Come ti voler conciare!
} 
likely adapted to the author's mother tongue. One example would be Dragut (1848) who did experience the Lingua Franca during his travels from 1540 to 1543, but only wrote about it 20 years later (Dragut 1848 quoted in Cifoletti 2004, 196) ${ }^{4}$. Another example would be De Brèves (1628 quoted in Cifoletti 2004, 202) ${ }^{5}$ who could have misheard the widely used Arabic expression xalâs (Cifoletti 2004, 202).

Hancock (1977) mentions that references to such languages were always made by "non-native speakers" who always were "speakers of lexically unconnected languages", and therefore the languages were "represented in the orthography of the recorders' tongue" (278). As a result, "this standardization leads to error", as pronunciation can easily be mixed up and the orthography of two different languages is never, or hardly ever, the same, which again leads to a distortion of the language described (ibid.). This is especially true for the Lingua Franca.

A further source would be the eyewitness reports that were popular from the $16^{\text {th }}$ to the $19^{\text {th }}$ century. These reports were mostly writings about the experiences and observations that captured Europeans made during their life in captivity. These reports were often written "with a Eurocentric and one-sided view of Lingua Franca" (Selbach 2008, 36). What is striking about these reports is that the perception of the Lingua Franca depended on the mother tongue of the author. Those people that were least familiar with the Lingua Franca always wrote more positively and impartially about it. The language available to the author not only influenced the attitude towards the Lingua Franca but also "the status, perception and even the assessment of the source of the lexicon of the Lingua Franca" (Selbach 2008, 44). According to Selbach, French authors more readily suggested French as the main source of the Lingua Franca, Italian authors most often stated that the Lingua Franca was a bastard or broken (Italian) tongue and only authors of other languages were more tolerant in this respect (ibid.).

What is also noteworthy at this point is that only travellers that had no immediate knowledge of the Lingua Franca wrote about it, especially in the earlier period (i.e. $16^{\text {th }}$ century), as that was the time of journeying abroad and writing about the experience gathered. In the later period the view of the Lingua Franca was always influenced by other factors, which led to a distorted view of the language. Those persons who had knowledge of the Lingua Franca or knew it well enough, hardly ever wrote about it because they did not see the sense in doing so. ${ }^{6}$

History itself, as argued above, is a valuable source as well: "Historical rather than linguistic evidence must provide the principle lead” (Hancock 1977, 279). Only by reconstructing the early history of the Lingua Franca and by concentrating on relevant historical aspects and situations that stimulated its use, spread, and development and

\footnotetext{
4 "Senor Dragut, usuanza de guerra!...Y mudanza de fortuna"

5 "Malta calas, Malta calas, San Ioan dormir"

6 The only exception being Haedo (1612 quoted in Cifoletti, 2004: 197-202) which presents most of our evidence about the Lingua Franca.
} 
then comparing it with the linguistic situation can a conclusion be reached. It is most essential to increase the available "historical knowledge" (Hancock 1977, 279) to establish the necessary "historical links" (ibid., 283) in order to be able to connect aspects of history and historical events that were responsible for shaping the linguistic traits of the Lingua Franca. Many linguistic puzzles could be solved if we were familiar with enough history and, of course, with what was relevant for the history of Lingua Franca. This could be the key to successfully explain the linguistic peculiarities of the Lingua Franca.

The problem that must be identified at this point is definitely the considerable amount of (historical) data that emerges. It is this large amount of historical data that makes quantifying the data a real problem, especially if historians such as Chaunu (1979) or Wansbrough (1996) are considered, who have written quite detailedly about historically relevant events concerning the Lingua Franca. To be more precise, some developments of the Lingua Franca can be explained and linked directly to historic events: e.g. Haedo (1612) reports that an expansion in Portuguese vocabulary occurred within a very short amount of time when thousands of Portuguese soldiers became captives (Haedo 1612 quoted in Cifoletti 2004, 198). In the case of the Portuguese vocabulary expansion it is abundantly clear which historical event caused this development, i.e. the 'Battle of Three Kings' in 1578. Unfortunately, not every linguistic trait of the Lingua Franca can immediately be applied to one specific historical event. Some developments can rather be ascribed to general developments of the area it was spoken in, e.g. Mediterranean piracy caused the thriving of the Lingua Franca in the so-called 'pirate strongholds' (Tunis, Tripoli, and Algiers), in which pirates/slavers used and captives/slaves were forced to use the Lingua Franca to communicate. Other (for the Lingua Franca itself) unrelated historical events, such as French becoming the dominant economic power in the Mediterranean, lead to the re-lexification of the Lingua Franca, followed by its final extinction. Thus, not only is it necessary to link Lingua Franca developments to historical events that occurred at that time (and in the geographical vicinity), but also to examine the possible outcomes of (unrelated) greater historical developments on the Lingua Franca itself (i.e. economic developments of the Mediterranean).

Ideally, developments of the Lingua Franca correlate highly with historical events. However, neither is this always obvious, nor can the question of what is important and what is not relevant be easily answered methodologically. Furthermore, the interpretation of earlier materials poses an additional problem as these materials "suffer from uncertain chronology" (Wansbrough 1996, 19). 


\section{Conclusion}

Therefore, we have to choose between either the lack of linguistic evidence of the Lingua Franca, the abundance of historical evidence for it, or the adapted version of it in poetry and prose. Making a choice is, however, problematic. All of these sources are important to reconstruct aspects, peculiarities, and features of the Lingua Franca. However, all cause immense difficulties in finding an appropriate, even probable, version of the development of the Lingua Franca. At all times, we must remember that historical "reconstruction of contact is of course frustrated by spatial lacunae and a notoriously conjectural chronology" (Wansbrough 1996, 63). What can be done about all these difficulties is to fill the gaps as well and as completely as possible by resorting to historical evidence. After all, historical reconstruction is certainly the best alternative for tracing the structural development of the Lingua Franca, as the historical point of view offers many more perspectives and can more easily fill gaps and lacunae that neither linguistic evidence nor poetry or prose can, due to their restricted documentation sources. This especially applies to the earlier period, as linguistic evidence is available only from the $16^{\text {th }}$ century onwards. Therefore, history can help a great deal here but only if one knows where to look. If we can reconstruct the history of the Lingua Franca we can use the linguistic evidence that is available to check if our theory can hold.

\section{References}

Agha, A. 2006. Language and Social Relations. New York: Cambridge University Press.

Alleyne, M. C. 1998. Roots of Jamaican Culture. Worcester: Pluto Press.

Ardener, E. 1971. "Social Anthropology and the Historicity of Historical Linguistics." In A.S.A. Monographs 10 - Social Anthropology and Language, edited by E. Ardener, 209-242. London: Tavistock Publications Limited.

Arends, J. 2002. “The Historical Study of Creoles and the Future of Creole Studies." Studies in Ethnolinguistics 9 - Pidgin and Creole Linguistics in the Twenty-First Century, edited by G. Gilbert, 49-68. New York: Peter Lang Publishing Inc.

Chaunu, P. 1979. [1969] "European Expansion in the Later Middle Ages." (Trans. Katharine Bertram). In Europe in the Middle Ages - Selected Studies 10., edited by R. Vaughan, Amsterdam/NewYork/Oxford: North Holland Publishing Company.

Cifoletti, G. 2004. La Lingua Franca Barbaresca. Roma: Il Calamo.

De Granda, G. 1976. "A Socio-Historical Approach to the Problem of Portuguese Creole in West Africa.” Linguistics 173: 11-22.

Foltys, C. 1984. "Die Belege der Lingua Franca." Neue Romania 1: 1-37.

Hall, R. A. 1966. Pidgin and Creole Languages. New York: Cornell University Press.

Hancock, I. F. 1977. "Recovering Pidgin Genesis: Approaches and Problems." Pidgin and Creole Linguistics, edited by A. Valdman, 277-294. Bloomington \& London: Indiana University Press.

Hymes, D (ed.) 1971. Pidginization and Creolization of Languages - Proceedings of a Conference beld at the University of the West Indies. London: Cambridge University Press 
Lang, G. 1992. “The Literary Settings of Lingua Franca (1300-1830).” Neophilologus 76: 64-76.

Le Page, R. B. 1961. "Conference on Creole Language Studies." in Creole Language Studies II - Proceedings of the Conference on Creole Language Studies, edited by R. B. Le Page, 123-128. London: Macmillan \& Co Ltd.

Monk, J. 2013. “Catalan language.” In Medieval Ibera: An Encyclopedia, edited by E. Michael Gerli, https://books.google.at/books?id = euVJAgAAQBAJ\&printsec $=$ frontcover\&dq $=$ Medieval $+\mathrm{I}$ beria + an + encyclopedia\&hl $=$ de\&sa $=$ X\&ved $=0$ CCsQ6AEwAGoVChMIm-Kjw5nyxwIVx7Q -UCh2n1wyL\#v= onepage\&q= Medieval\%20Iberia\%20an\%20encyclopedia\&f = false (accessed 25 September 2015).

Sapir, E. 1921. Language: An introduction to the study of speech. New York: Harcourt, Brace and Company.

Schuchardt, H. 1909. “Die Lingua Franca.” Zeitschrift für Romanische Philologie 33: 441-461.

Schuchardt, H. 1979. [1909] On Lingua Franca. (Trans. Thomas L. Markey). In The ethnography of variation: Selected writings on pidgeons and creoles, edited by T. L. Markey, 26-47. Ann Arbor: Karoma.

Selbach, R. 2008. "The Superstrate is not always the Lexifier: Lingua Franca in the Barbary Coast 1530-1830." In Roots of Creole Structures - Weighing the Contribution of Substrates and Superstrates, edited by S. Michaelis, 29-58. Amsterdam/Philadelphia: John Benjamins Publishing Company.

Thompson, R. W. 1961. "A Note on some Possible Affinities between the Creole Dialects of the Old World and those of the New." In Creole Language Studies II Proceedings of the Conference on Creole Language Studies, edited by R. B. Le Page, 107-113. London: Macmillan \& Co Ltd.

Voorhoeve, J. 1961. "A Project for the Study of Creole Language History in Surinam.” In Creole Language Studies II - Proceedings of the Conference on Creole Language Studies, edited by R. B. Le Page, 99-106. London: Macmillan \& Co Ltd.

Wansbrough, J. E. 1996. Lingua Franca in the Mediterranean. Surrey: Curzon Press.

Whinnom, K. 1965. "The Origin of the European-based Creoles and Pidgins.” Orbis 15: 509-527.

Whinnom, K. 1971 "Linguistic Hybridization and the 'Special Case' of Pidgins and Creoles." In Pidginization and Creolization of Languages - Proceedings of a Conference held at the University of the West Indies, edited by D. Hymes, 91-116. London: Cambridge University Press.

Whinnom, K. 1984. "Lingua Franca: Historical Problems." In Pidgin and Creole Linguistics, edited by A. Valdman, 295-310. Bloomington: Indiana University Press.

Wiener, N. 1948. Cybernetics. Cambridge, Mass.: MIT Press. 1961 (2nd. ed.) 